DR. LAI WEI (Orcid ID : 0000-0003-2326-1257)

DR. VEDRAN PAVLOVIC (Orcid ID : 0000-0002-9475-7201)

PROF. JIA-HORNG KAO (Orcid ID : 0000-0002-2442-7952)

DR. PIETRO LAMPERTICO (Orcid ID : 0000-0002-1026-7476)

PROF. YUN-FAN LIAW (Orcid ID : 0000-0003-0664-9372)

PROF. GEORGE V. PAPATHEODORIDIS (OrCid ID : 0000-0002-3518-4060)

Article type : Original Paper

\title{
Genetic variation in FCER1A predicts peginterferon alfa-2a-induced hepatitis B surface antigen clearance in East Asian patients with chronic hepatitis B
}

Lai Wei, ${ }^{1,2}$ Vedran Pavlovic, ${ }^{3}$ Aruna T. Bansal, ${ }^{4}$ Xiaoping Chen, ${ }^{5}$ Graham R. Foster, ${ }^{6}$ Hua He, ${ }^{3}$ Jia-Horng Kao, ${ }^{7}$ Pietro Lampertico, ${ }^{8}$ Yun-Fan Liaw, ${ }^{9}$ Adriana Motoc, ${ }^{10}$ George V. Papatheodoridis, ${ }^{11}$ Teerha Piratvisuth, ${ }^{12}$ Robert Plesniak, ${ }^{13}$ and Cynthia Wat ${ }^{3}$

${ }^{1}$ Peking University People's Hospital, Beijing, China

${ }^{2}$ Peking University Hepatology Institute, Beijing, China

${ }^{3}$ Roche Products Ltd, Welwyn Garden City, UK

This article has been accepted for publication and undergone full peer review but has not been through the copyediting, typesetting, pagination and proofreading process, which may lead to differences between this version and the Version of Record. Please cite this article as doi: $10.1111 /$ jvh. 13107

This article is protected by copyright. All rights reserved. 
${ }^{4}$ Acclarogen Ltd, Cambridge, UK

${ }^{5}$ Guangdong General Hospital, Guangzhou, China

${ }^{6}$ Queen Mary's University of London, Bart's and The London School of Medicine, London, UK

${ }^{7}$ Department of Internal Medicine, National Taiwan University Hospital, Taipei, Taiwan; ${ }^{8}$ AM \& A Migliavacca Center for Liver Disease, Gastroenterology and Hepatology Unit, Fondazione IRCCS Ca' Granda Ospedale Maggiore Policlinico, Università degli Studi di Milano, Milan, Italy

${ }^{9}$ Liver Research Unit, Chang Gung Memorial Hospital, Chang Gung University College of Medicine, Taipei, Taiwan

${ }^{10}$ Infectious and Tropical Diseases Hospital "Dr. Victor Babes", Bucharest, Romania

${ }^{11}$ Department of Gastroenterology, Medical School of National \& Kapodistrian

University of Athens, Laiko General Hospital, Athens, Greece

${ }^{12} \mathrm{NKC}$ Institute of Gastroenterology and Hepatology, Prince of Songkla University, Hat-Yai, Thailand

${ }^{13}$ University of Rzeszów, Faculty of Medicine, Clinical Department Of Infectious

Diseases, Łańcut, Poland

\section{Correspondence}

Lai Wei

Peking University Hepatology Institute

Peking University People's Hospital

Beijing, China

Phone: 8610-88325730

Email: weilai@pkuph.edu.cn 
Suggested running title: Genetic variation and hepatitis B response

\section{Author Contributions}

- Study concept and design: LW, GRF, HH, TP, CW.

- Acquisition of data: LW, GRF, J-HK, RP.

- Analysis and interpretation of data: LW, VP, ATB, J-HK, GVP, TP, CW.

- Drafting of the manuscript: VP.

- Critical revision of the manuscript for important intellectual content: LW, ATB, XC, GRF, HH, J-HK, PL, Y-FL, AM, GVP, TP, RP, CW.

- All authors had access to the study data and reviewed and approved the final manuscript.

- Agreement to be accountable for all aspects of the work in ensuring that questions related to the accuracy or integrity of any part of the article are appropriately investigated and resolved: all authors.

\section{DISCLOSURES}

Lai Wei has been a speaker, consultant, or advisory board member for AbbVie, BMS, Gilead, Johnson \& Johnson and GSK. Cynthia Wat is an employee of Roche and declares ownership of Roche stock. Vedran Pavlovic and Hua He were employed by Roche. Aruna Bansal has been a consultant for Roche. Graham Foster has been a speaker and consultant for Roche, AbbVie, BMS, Merck, Gilead, Janssen, Tekmira and Alnylam. Pietro Lampertico has been an advisory board member or speaker for Roche, BMS, Gilead GlaxoSmithKline and MSD. Georgios 
Papatheodoridis has been an advisory board member, consultant or speaker for Roche, AbbVie, Boehringer Ingelheim, BMS, Gilead, GlaxoSmithKline, Janssen, MSD and Novartis and has received grant or research support from AbbVie, BMS, Gilead and Janssen. Teera Piratvisuth has been an advisory board member or speaker for Roche, BMS, MSD, Novartis and GSK and has received grant/research support from Roche, BMS, MSD, Novartis, Fibrogen and Bayer. Xiaoping Chen, JiaHorng Kao, Yun-Fan Liaw, Adriana Motoc and Robert Plesniak have no conflicts of interest to disclose.

\section{Funding information}

This research was funded by F. Hoffmann-La Roche Ltd, Basel, Switzerland. F. Hoffmann-La Roche Ltd were involved in study design; in the collection, analysis and interpretation of data; in the writing of the report; and in the decision to submit the article for publication, in conjunction with the authors.

\section{Clinical trial number}

Clinicaltrials.gov NCT01855997

\section{ACKNOWLEDGMENTS}

This research was funded by F. Hoffmann-La Roche Ltd, Basel, Switzerland. 
We would like to thank all patients, their families, the investigators and the nurses who participated in these trials. The authors would like to thank the investigators of the studies included in the analysis for their contribution to the generation of data. Support for third-party writing assistance for this manuscript, furnished by Blair Jarvis, MSc, ELS, of Health Interactions, was provided by Roche Products Ltd, Welwyn Garden City, UK.

\section{ABSTRACT}

In a multicenter, genome-wide association study to identify host genetic factors associated with treatment response in adult chronic hepatitis B patients, genotype data were obtained by microarray analysis from 1669 patients who received peginterferon alfa-2a for $\geq 24$ weeks with/without a nucleos(t)ide analog. Treatment response was assessed at least 24 weeks post-treatment, using serological and/or virological endpoints. Thirty-six single-marker analyses and a gene-by-gene analysis were conducted. No single nucleotide polymorphisms (SNPs) achieved genomewide significance $\left(P<5 \times 10^{-8}\right)$ in single-marker analyses, but suggestive associations $\left(P<1 \times 10^{-5}\right)$ were identified for 116 SNPs. In gene-by-gene analyses, one gene, FCER1A (rs7549785), reached genome-wide significance $\left(P=2.65 \times 10^{-8}\right)$ in East Asian patients for hepatitis B surface antigen (HBsAg) clearance, with a moderate effect size (odds ratio $=4.74$ ). Eleven of 44 carriers $(25 \%)$ of the A allele at rs7549785 achieved HBsAg clearance compared with 69/1051 (7\%) noncarriers. FCER1A encodes the alpha subunit of the immunoglobulin $\mathrm{E}$ receptor. In a post hoc analysis of a homogenous patient subset, the strongest intra-genic association was for $r$ 77712322 (POLR3G, $P=7.21 \times 10^{-7}$ ). POLR3G encodes the G subunit of the 
Polymerase (RNA) III enzyme, involved in sensing and limiting infection by intracellular bacteria and DNA viruses, and as a DNA sensor in innate immune responses. FCER1A (rs7549785), and possibly POLR3G (rs7712322), are shown to be associated with peginterferon alfa-2a response in adult patients with chronic hepatitis B. Independent confirmation of these findings is warranted (clinicaltrials.gov number NCT01855997).

\section{KEYWORDS}

chronic hepatitis B, peginterferon alfa-2a, genetic variation, response

Abbreviations: $\mathrm{CHB}$, chronic hepatitis $\mathrm{B}$; $\mathrm{CHC}$, chronic hepatitis C; EA, East Asian; GWAS, genome-wide association study; NA, nucleos(t)ide analog; SKAT, SNP-set (Sequence) Kernel Association Test; SNP, single nucleotide polymorphism.

\section{I INTRODUCTION}

Chronic hepatitis $\mathrm{B}(\mathrm{CHB})$ is a major global public health problem. An estimated 240 million people are chronically infected worldwide and 650,000 die each year from $\mathrm{CHB}$ sequelae. ${ }^{1}$ The prevalence of $\mathrm{CHB}$ varies widely by geography and is substantially higher in Asia (>8\%) than in Western Europe and North America $(\leq 2 \%) .{ }^{2}$ Several genome-wide association studies (GWAS) have revealed the influence of host genetic factors on the natural history of $\mathrm{CHB}$; variations in the human leukocyte antigen (HLA)-DP region were shown to be associated with $\mathrm{CHB}$ 
development and spontaneous hepatitis B surface antigen (HBsAg) clearance..$^{3-7}$ Moreover, variations in KIF1B, STAT4 and GLB1 genes were implicated in the development of hepatocellular carcinoma (HCC) and/or cirrhosis. ${ }^{8-10}$

Current CHB treatments aim to achieve sustained suppression of hepatitis B virus (HBV) replication, in order to prevent disease progression and CHB sequelae, namely liver cirrhosis, hepatic decompensation and HCC. While peginterferon alfa2a [40KD] (PEG-IFN, PEGASYS ${ }^{\circledR}$; Roche, Basel, Switzerland) is recommended as a first-line therapy, it is associated with a high treatment burden (weekly subcutaneous injections for 1 year) and with frequent and bothersome side effects, and durable treatment response is only observed in approximately one-third of patients. ${ }^{11-13}$ Thus, the ability to identify patients likely to respond to PEG-IFN is of significant clinical value, as it would allow a personalized healthcare approach, minimize unnecessary treatment-exposure in patients unlikely to respond to therapy, and increase the costeffectiveness of treatment. Although host and viral factors for prediction of response have been extensively studied, the prediction of response remains imperfect. ${ }^{14-16}$

Very few GWAS have explored the impact of host genetic factors on treatment response in CHB patients. While variations in the IL28B gene have been shown to be strongly associated with spontaneous (as well as interferon-induced) viral clearance in patients with chronic hepatitis $C,{ }^{17,18}$ the role for IL28B in the PEG-IFN response in patients with $\mathrm{CHB}$ is unclear. ${ }^{19-21}$ Two studies have suggested that variations in the HLA-DQA2 and SLC16A9 may be associated with PEG-IFN response in $\mathrm{CHB}$ patients, ${ }^{7,22}$ although both studies were limited in size and the 
findings have not yet been validated. The objective of the current GWAS was to identify genetic polymorphisms predictive of PEG-IFN response within a large cohort of patients with $\mathrm{CHB}$.

\section{I MATERIALS AND METHODS}

\subsection{Patients}

The PEG-BE-YOND (GV28855, NCT01855997) study was a phase IV, multicenter, exploratory GWAS in adult patients with CHB who received PEG-IFN treatment, at $180 \mu \mathrm{g} /$ week for $\geq 24$ weeks, with/without a nucleos(t)ide analog (NA). All participating patients provided written informed consent and the study was conducted in accordance with the principles of the Declaration of Helsinki and Good Clinical Practice.

Patients enrolled between August 2013 and November 2014 from three ongoing or completed clinical trials (MV22430, NCT00927082; ${ }^{23}$ ML21827, NCT00922207; ${ }^{24}$ ML18253, NCT01095835 ${ }^{25}$ ) or clinical practice across 105 centers in 20 countries located in the European Union or Asia-Pacific region. Patients coinfected with hepatitis $\mathrm{A}$ or $\mathrm{C}$ or with human immunodeficiency virus were excluded from the clinical trials and were ineligible for recruitment from clinical practice. The trials also excluded patients with other severe concomitant diseases including cardiac, respiratory, and psychiatric illnesses. Assuming a 2:1 ratio of nonresponders to responders in an ethnically homogenous cohort, a sample size of 1200 provides $>90 \%$ power to detect common genetic variants (frequency $>0.2$ ) with a small effect size (odds ratio $>1.5$ ). 


\subsection{Genotyping and quality control}

Whole blood samples were either prospectively collected or, where available, obtained from previously collected Roche Clinical Repository samples for patients in ongoing/completed clinical trials. Genomic DNA was extracted from peripheral blood lymphocytes using standard procedures at a central laboratory, Shanghai Biotechnology Corporation (Pudong, Shanghai, China). Genotyping was performed using Illumina OmniExpressExome microarray (Illumina, Inc., San Diego, CA, USA), which includes $>750,000$ non-exonic single nucleotide polymorphisms (SNPs) and $>250,000$ exonic markers.

Quality checks were conducted on unfiltered GWAS data. Patients whose genetic data satisfied the following criteria were retained for statistical analyses: $<30 \%$ heterozygosity genome-wide; $<5 \%$ missing genotype data; reported sex consistent

with X-chromosome data; $<30 \%$ genotype concordance with another sample. Quality checks were also conducted by marker. Markers with $>5 \%$ missing data were excluded.

\subsection{Statistical analysis}

Treatment response was defined according to six serological and/or virological efficacy endpoints: hepatitis B 'e' antigen (HBeAg) or HBsAg seroconversion in HBeAg-positive patients (endpoint 1); HBeAg seroconversion plus HBV DNA <2000 $\mathrm{IU} / \mathrm{mL}$ or HBsAg clearance in HBeAg-positive patients (endpoint 2); and HBV DNA $<2000 \mathrm{IU} / \mathrm{mL}$ or HBsAg clearance in HBeAg-negative patients (endpoint 3). Endpoint 
4 (the combination of endpoints 1 and 3), endpoint 5 (the combination of endpoints 2 and 3) and endpoint 6 (HBsAg clearance) pertained to all patients combined. The efficacy endpoints were assessed $\geq 24$ weeks post-treatment, whereby available data closest to (but not less than) the target 24-weeks post-treatment timepoint was used in the evaluation of each endpoint. This methodology was implemented as it was anticipated that available data on post-treatment assessments would likely be variable for patients enrolled from clinical practice.

Analysis populations were derived based on principal component analysis of ancestry, with the aim of determining clusters of individuals who shared a homogenous genetic background. A suitable set of GWAS markers for ancestry analysis was obtained as follows. Markers were excluded if they had minor allele frequency $<5 \%$ or corresponded to regions with known high linkage disequilibrium or inversion. To facilitate merging, markers encoding complementary base-changes were also removed. The remaining markers were thinned such that all SNPs within a window of size 1000 had $r^{2}<0.25$. HapMap version 3 data were downloaded for the resultant marker set ${ }^{26-28}$ and data were merged, taking care to resolve any strand differences between the two sources. Any marker not available for HapMap subjects was excluded from the merged file. Principal component of ancestry was applied, and plots were colored according to bio-geographic origin. A scree plot was used to show the contributions of the first ten principal components. 
Considering most patients were anticipated to be enrolled from China, three analysis populations were prespecified: the overall (ALL) patient population, the East Asian (EA) population who shared a common genetic background with the Chinese or Japanese HapMap reference individuals, and the non-East Asian (non-EA) population.

All markers were tested for departure from Hardy-Weinberg Equilibrium by chisquare test. Univariate/single-marker association analyses were conducted using multivariate logistic regression adjusted for covariates under both additive and dominant modes of inheritance. Baseline covariates considered in the model included age, sex, $\log _{10}$ HBV DNA level, $\log _{10}$ alanine aminotransferase activity, HBV genotype, concomitant use of NA, study, and the first and second principal components of ancestry. Multi-marker/gene-by-gene analysis of rare and non-rare variants was conducted using the SNP-set (Sequence) Kernel Association Test (SKAT). ${ }^{29,30}$ The unit of analysis for this aggregate technique was a gene region. Rare and common SNPs were grouped using physical location and known gene boundaries.

The genomic control lambda was calculated for each GWAS analysis and quantilequantile plots were examined. Markers with unadjusted $P$-values $<1 \times 10^{-5}$ and $<5 \times 10^{-8}$ were considered suggestive and of genome-wide significance, respectively. No $P$-value adjustment was made for multiple endpoints or rounds of analysis due to the exploratory nature of the study. Statistical analyses were performed using PLINK v1.07 (http://pngu.mgh.harvard.edu/purcell/plink/), EIGENSOFT v4.0, ${ }^{31,32}$ and R v3.0.2 (https://www.r-project.org/) software. 


\section{I RESULTS}

\subsection{Patient demographics and baseline characteristics}

Genotype data were available for 1669 patients (564 [34\%] from clinical trials and 1105 [66\%] from clinical practice). Thirty-three patients were excluded from analyses as their genetic data failed quality control checks: four samples had $\geq 5 \%$ missing genotypes, six samples had X-chromosome homozygosity inconsistent with reported sex, and 23 sample-pairs had high genotype concordance consistent with firstdegree familial relationship (one of each pair was excluded).

Baseline characteristics of 1636 individuals included in the overall population are shown in Table 1. The majority of patients were male (72\%), HBeAg-positive (55\%), and of Asian/Oriental race (68\%), with a mean age of 39 years and infected with HBV genotype B (21\%) or C (28\%). Principal component analysis of ancestry shows the study participants were a genetically more diverse cohort than the HapMap reference, with EA $(n=1120)$ and non-EA $(n=516)$ population subgroups depicted (Figure 1).

A summary of efficacy outcomes according to analysis population is shown in Table 2. In $\mathrm{HBeAg}$-positive patients, the incidence of $\mathrm{HBeAg}$ or $\mathrm{HBsAg}$ seroconversion (endpoint 1) was $30 \%(276 / 907)$ overall, and $31 \%$ and $24 \%$ in EA and non-EA patients respectively. In HBeAg-negative patients, the incidence of HBV DNA $<2000$ IU/mL or HBsAg clearance (endpoint 3) was $62 \%$ (393/638) overall, and $78 \%$ and $50 \%$ in EA patients and non-EA patients, respectively. The incidence of HBsAg clearance (endpoint 6) was 7\% (104/1399) overall, with similar incidence in EA and non-EA subgroups. Notably, three analysis subgroups contained fewer than 
30 patients, such that statistical comparisons of response rates between subgroups were not expected to be informative, due to low statistical power.

\subsection{Single-marker analyses}

Thirty-six univariate association analyses were conducted (ie, three analysis populations, six response endpoints, two modes of inheritance). No SNP achieved genome-wide significance $\left(P<5 \times 10^{-8}\right)$. One hundred and sixteen SNPs, the majority of which lay in noncoding intergenic regions, were suggestive of an association with PEG-IFN response $\left(P<1 \times 10^{-5}\right): 24,16,18,23,26$ and nine SNPs associated with efficacy endpoints 1 to 6 , respectively. A total of 27 SNPs mapped to 24 genes (Table 3), of which $r s 7549785$ (FCER1) provided the strongest association $(P<1 \times$ $10^{-6}$ ) for endpoint 6 . In contrast to the other 26 identified SNPs, rs7549785 is an uncommon variant (minor allele frequency $=2 \%$ ) with a large genetic effect size (odds ratio $=8.2$ ).

Manhattan and Quantile-Quantile (QQ) plots for HBsAg clearance (endpoint 6) in the EA population under the additive model of inheritance are shown in Figure 2. A single marker on chromosome 1 (rs7549785) had a $P$-value of $4.83 \times 10^{-7}$ which surpassed the suggestive threshold for association with PEG-IFN response. The $Q Q$ plot supports the significance of this SNP, wherein the distribution of observed $P$ values closely follows the expected $P$-values (thereby excluding presence of confounders) until the sharp tail at the end (driven by rs75498SNP). The association was absent in the non-EA population. rs7549785 maps to the 3'UTR of the gene for 
the Fc fragment of immunoglobulin E (lgE) high affinity I receptor for alpha polypeptide (FCER1A), located on chromosome 1. Similar results were obtained in the dominant model of inheritance (not shown).

\subsection{Gene-by-gene analyses}

One gene, FCER1A, reached genome-wide significance $\left(P=2.65 \times 10^{-8}\right)$ in the EA population for HBsAg clearance. The result was driven by a single low-frequency $(2 \%)$ marker, with a moderate effect size (estimated odds ratio $=4.74)$. Eleven of the 44 carriers (25\%) of the rs7549785 A allele achieved HBsAg clearance compared with $69 / 1051(7 \%)$ noncarriers. The association was not observed in the non-EA population.

The genomic context of the FCER1A gene is shown in Figure 3. Markers located within 10 kilobases on either side of $r s 7549785$ SNP were not associated with HBsAg clearance (Figure 3A). This is explained by linkage disequilibrium phenomena (Figure 3B), whereby rs7549785 falls outside of a block of inheritance (ie, a portion of DNA-containing genes that are frequently inherited in association with each other) that spans the rest of the FCER1A gene.

This article is protected by copyright. All rights reserved. 


\subsection{Post hoc re-analysis in an homogenous patient subset}

Review of the study data confirmed a moderate degree of phenotypic heterogeneity, with approximately $20 \%$ of patients receiving prolonged (>58 weeks) PEG-IFN treatment duration. Subsequently, a post hoc genome-wide analysis was conducted in a targeted, more homogenous, subset of patients who satisfied additional criteria: PEG-IFN treatment duration of 48 weeks ( \pm 12 weeks), more stringent visit windows for serology data at baseline (PEG-IFN start date -24 to +4 weeks) and posttreatment follow-up (PEG-IFN stop date +12 to +36 weeks), no treatment with NA during post-treatment follow-up.

The post hoc homogenous subset included 1132/1636 (69\%) patients, consisting of 716 and 416 EA and non-EA patients, respectively. A summary of the efficacy outcomes according to analysis population is shown in Supplementary Table 1. In general, the response rates were comparable to, or slightly higher than, those in the per-protocol population. Notably, eight analysis subgroups contained fewer than 30 patients.

Consistent with the primary analysis, no marker achieved genome-wide significance in the single-marker analysis. Seventy-two SNPs, the majority of which were intergenic, were suggestive $\left(P<1 \times 10^{-5}\right)$ of an association with PEG-IFN response: $14,5,6,17,21$ and nine SNPs associated with efficacy endpoints 1 to 6 , respectively. Fourteen SNPs mapped to 13 genes (Supplementary Table 2), of which rs7712322 provided the strongest association $\left(P<1 \times 10^{-6}\right)$ for endpoints 1 and 4 . 
rs7712322 maps to the Polymerase (RNA) III Subunit G (POLR3G) gene located on chromosome 5 .

None of the markers identified in the post hoc analysis match those identified in the per-protocol primary analysis. No associations exceeded the threshold for genomewide significance in the gene-by-gene analysis.

\section{I DISCUSSION}

To our knowledge, we have conducted the largest GWAS specifically exploring the influence of genetic factors on PEG-IFN response in patients with $\mathrm{CHB}$. The natural history of CHB has been well studied in a genome-wide setting, and variations within HLA-DP, KIF1B, STAT4 and GLB1 genes have been shown to be significantly associated with development and/or progression of $\mathrm{CHB} .{ }^{3-10}$ However, none of the aforementioned genes were identified as being associated with PEG-IFN response in the current study.

In the single-marker analysis, we identified a large number (116 and 72 in perprotocol and post hoc analyses, respectively) of suggestive associations $\left(P<1 \times 10^{-}\right.$

$\left.{ }^{5}\right)$ with PEG-IFN response, the majority of which were located in noncoding intergenic regions. It is unknown whether one or more of the identified intergenic markers may play a functional role; for example, in terms of regulating gene expression. Forty-one markers mapped to within the boundaries of 37 genes, of 
which the strongest associations $\left(P<1 \times 10^{-6}\right)$ were for $r s 7549785$ (FCER1) and rs7712322 (POLR3G). The identified associations are not likely to be due to confounders as the GWAS model was adjusted for several known predictors of PEGIFN response (eg, age, HBV genotype, baseline HBV DNA level), and the QQ plots did not suggest presence of bias/confounders (that would manifest as a constant deviation from the expected $P$-value distribution $[X Y]$ line).

The FCER1A gene encodes the alpha subunit of the IgE Fc receptor, which is involved in the initiation of the allergic response. ${ }^{33}$ When two or more high-affinity $\operatorname{lgE}$ receptors are brought together by allergen-bound IgE molecules, mediators such as histamine are released. Our analysis suggests that this gene may also exert an influence on whether a patient with CHB may achieve HBsAg clearance, although the exact underlying mechanism remains unclear. The POLR3G gene encodes the G subunit of the Polymerase (RNA) III enzyme, which catalyzes the transcription of DNA into RNA. It plays a key role in sensing and limiting infection by intracellular bacteria and DNA viruses, and acts as nuclear and cytosolic DNA sensor involved in innate immune response. ${ }^{34}$ Interestingly, this gene has previously been found to be associated with decreased hepatitis $\mathrm{C}$ virus replication. ${ }^{35}$

Some of the remaining genes identified in the current study have previously been implicated directly or indirectly with HBV-associated HCC, including von Willebrand Factor ( $v W F$ ( $r s 5216312)$, LASP1 (rs646097) and CENPO (rs1550116). vWF is a recognized biomarker of tumor development in HBV-associated HCC, LASP1 is involved in proliferation and migration of hepatoma cells, and CENP-A expression is upregulated in hepatoma cells. ${ }^{36-38}$ 
Conversely, some genes shown in previous studies to be associated with PEG-IFN response were not identified in this analysis. Notably, a major scientific finding via GWAS was that variations in the IL28B gene are strongly associated with treatment outcome in patients with chronic hepatitis C. ${ }^{17}$ Although few studies proposed IL28B plays a similar role in $\mathrm{CHB},{ }^{19,20}$ and other studies show no association, ${ }^{21}$ these findings were not validated in the present study. Further, we did not identify SLC16AP as being associated with PEG-IFN response, a result which is contrary to a previous report of an association with HBsAg clearance in a small cohort of patients treated with PEG-IFN and adefovir. ${ }^{22}$ Similarly, no association between rs9276370 and response was identified in this analysis, contrary to a report of an association with response to antiviral treatment in Taiwanese patients with $\mathrm{CHB} .^{7}$ The reasons for these differences are unclear; they may be due to differences in genotyping platform, patient characteristics, treatment response definition, study population size and genetic heterogeneity. It may be that the results of previous small studies were false-positive findings, or that the SNPs previously identified are real but of small effect size, thus missed in our study.

No SNP achieved genome-wide significance in the single-marker analysis for any treatment endpoint. However, in the prespecified gene-by-gene analysis, the FCER1A gene was associated with HBsAg clearance in EA patients treated with PEG-IFN. The association was driven by a single low-frequency marker (rs7549785) in the 3'UTR of the FCER1A gene, with a moderate effect size (odds ratio 4.74). The minor allele frequency of $r s 7549785$ was $6 \%, 2 \%$ and $15 \%$ in overall, EA, and nonEA populations, respectively. There was no association between this SNP and PEG- 
IFN response in non-EA patients, possibly due to low statistical power of this subanalysis (there were only 24 non-EA responders for endpoint 6). Likewise, this marker was not identified in the post hoc analysis, possibly because of the smaller post hoc analysis population. If the association between rs7549785 and HBsAg clearance is confirmed, it may have arisen due to the presence of one or more causal variants in linkage disequilibrium (co-inherited) with the tested marker.

There are several limitations with our study. The low number of patients in some analyses resulted in low statistical power; thus, modest effects may have been missed. Further, review of study data confirmed the presence of moderate phenotypic heterogeneity. GWAS are particularly sensitive to phenotypic heterogeneity; $20 \%$ heterogeneity can result in genome-wide significant SNPs to become unequivocal, while $50 \%$ heterogeneity results in a three-fold increase in sample size requirements (ie, reduced study power).${ }^{39}$ While we conducted a post hoc re-analysis in a more homogenous subset, the derived subset was approximately $30 \%$ smaller, meaning these analyses had potentially reduced statistical power. This may account for the lack of correlation between markers identified in the per-protocol and post hoc analyses. Covariates such as baseline HBsAg level and virus mutations, which are not included in the current model, may also influence response to peginterferon. ${ }^{40-42}$ Moreover, due to the complexity of CHB treatment endpoints and the exploratory nature of the study, a large number of analyses were conducted without $P$-value adjustment for multiplicity. Such a strategy, although comprehensive, increases type I error and likelihood of falsepositive findings. Finally, the study design consisted only of a one-stage discovery GWAS, and there was no independent cohort to validate the study findings. 
In conclusion, our findings demonstrate the need for very large cohorts to conduct pharmacogenetic response analyses in a heterogenous disease such as $\mathrm{CHB}$. Although no markers achieved genome-wide significance in the single-marker analysis, 37 genes were found to be suggestively associated with PEG-IFN response. Two novel genes identified with strongest associations $\left(P<1 \times 10^{-6}\right)$ were FCER1A (rs7549785) and POLR3G (rs7712322), and FCER1A reached genomewide-significance $\left(P=2.65 \times 10^{-8}\right)$ in a gene-by-gene analysis for HBsAg clearance in EA patients. The genetic basis of PEG-IFN response in CHB is definitely not simple or monogenic; rather, it appears to be highly polygenic and may have important, as yet unknown, environmental components. Independent replication of the study findings is required and further interrogation of genomic context and potential biological rationale for these findings is warranted.

\section{REFERENCES}

1. World Health Organization (WHO). Hepatitis B fact sheet No 204. July 2015. Available at: http://who.int/mediacentre/factsheets/fs204_Jul2014/en/. Accessed May 21, 2018.

2. Dienstag JL. Hepatitis B virus infection. N Engl J Med. 2008;359:1486-1500.

3. Kamatani $\mathrm{Y}$, Wattanapokayakit $\mathrm{S}$, Ochi $\mathrm{H}$, et al. A genome-wide association study identifies variants in the HLA-DP locus associated with chronic hepatitis B in Asians. Nat Genet. 2009;41:591-595.

4. Guo X, Zhang Y, Li J, et al. Strong influence of human leukocyte antigen (HLA)DP gene variants on development of persistent chronic hepatitis $B$ virus carriers in the Han Chinese population. Hepatology. 2011;53:422-428.

5. Mbarek $\mathrm{H}$, Ochi $\mathrm{H}$, Urabe $\mathrm{Y}$, et al. A genome-wide association study of chronic hepatitis B identified novel risk locus in a Japanese population. Hum Mol Genet. 2011;20:3884-3892.

6. Nishida N, Sawai H, Matsuura K, et al. Genome-wide association study confirming association of HLA-DP with protection against chronic hepatitis B and viral clearance in Japanese and Korean. PLoS One. 2012;7:e39175. 
7. Chang SW, Fann CS, Su WH, et al. A genome-wide association study on chronic HBV infection and its clinical progression in male Han-Taiwanese. PLoS One. 2014;9:e99724.

8. Zhang H, Zhai Y, Hu Z, et al. Genome-wide association study identifies 1p36.22 as a new susceptibility locus for hepatocellular carcinoma in chronic hepatitis $B$ virus carriers. Nat Genet. 2010;42:755-758.

9. Wang WT, Li Z, Shi M, et al. Association of the GLB1 rs4678680 genetic variant with risk of HBV-related hepatocellular carcinoma. Oncotarget. 2016;7:56501-56507.

10. Jiang DK, Ma XP, Wu X, et al. Genetic variations in STAT4,C2,HLA-DRB1 and HLA-DQ associated with risk of hepatitis B virus-related liver cirrhosis. Sci Rep. 2015;5:16278.

11. Marcellin P, Lau GK, Bonino F, et al. Peginterferon alfa-2a alone, lamivudine alone, and the two in combination in patients with $\mathrm{HBeAg}$-negative chronic hepatitis B. N Engl J Med. 2004;351:1206-1217.

12. Lau GK, Piratvisuth T, Luo KX, et al. Peginterferon alfa-2a, lamivudine, and the combination for HBeAg-positive chronic hepatitis B. N Engl J Med. 2005;352:26822695.

13. Liaw YF, Jia JD, Chan HL, et al. Shorter durations and lower doses of peginterferon alfa-2a are associated with inferior hepatitis $B$ e antigen seroconversion rates in hepatitis $\mathrm{B}$ virus genotypes $\mathrm{B}$ or $\mathrm{C}$. Hepatology. 2011;54:1591-1599.

14. European Association For The Study Of The Liver. EASL clinical practice guidelines: Management of chronic hepatitis B virus infection. J Hepatol. 2012;57:167-185.

15. Sarin SK, Kumar M, Lau GK, et al. Asian-Pacific clinical practice guidelines on the management of hepatitis B: a 2015 update. Hepatol Int. 2016;10:1-98.

16. Konerman MA, Lok AS. Interferon treatment for hepatitis B. Clin Liver Dis. 2016; 20:645-665.

17. Ge D, Fellay J, Thompson AJ, et al. Genetic variation in IL28B predicts hepatitis C treatment-induced viral clearance. Nature. 2009;461:399-401.

18. Thomas DL, Thio CL, Martin MP, et al. Genetic variation in IL28B and spontaneous clearance of hepatitis C virus. Nature. 2009;461:798-801.

19. Sonneveld MJ, Wong VW, Woltman AM, et al. Polymorphisms near IL28B and serologic response to peginterferon in $\mathrm{HBeAg}$-positive patients with chronic hepatitis B. Gastroenterology. 2012;142:513-520.e1.

20. Lampertico $\mathrm{P}$, Viganò $\mathrm{M}$, Cheroni $\mathrm{C}$, et al. IL28B polymorphisms predict interferon-related hepatitis $B$ surface antigen seroclearance in genotype $D$ hepatitis B e antigen-negative patients with chronic hepatitis B. Hepatology. 2013;57:890-896.

This article is protected by copyright. All rights reserved. 
21. Wei L, Wedemeyer H, Liaw Y-F, et al. No association between IL28B genotype and response to peginterferon alfa-2a (40KD) in $\mathrm{HBe}$ antigen-positive and $\mathrm{HBe}$ antigen-negative patients with chronic hepatitis $B$ in three large randomized clinical studies. Hepatology. 2013;58:647A-648A.

22. Jansen $L$, de Niet A, Stelma F, et al. HBsAg loss in patients treated with peginterferon alfa-2a and adefovir is associated with SLC16A9 gene variation and lower plasma carnitine levels. J Hepatol. 2014;61:730-737.

23. Chuang WL, Jia J, Chan HLY, et al. Responses are durable for up to 5 years after completion of peginterferon alfa-2a treatment in hepatitis $\mathrm{B}$ e antigen-positive patients. Aliment Pharmacol Ther 2018:47:1306-1316.

24. Hsu CW, Su WW, Lee CM, et al. Phase IV randomized clinical study: Peginterferon alfa-2a with adefovir or entecavir pre-therapy for HBeAg-positive chronic hepatitis B. J Formos Med Assoc 2018;117:588-597.

25. Lampertico P, Viganò M, Di Costanzo GG, et al. Randomised study comparing 48 and 96 weeks peginterferon $\alpha-2 a$ therapy in genotype D HBeAg-negative chronic hepatitis B. Gut 2013;62:290-298.

26. International HapMap Consortium. The International HapMap Project. Nature. 2003;426:789-796.

27. International HapMap Consortium. A haplotype map of the human genome. Nature. 2005;437:1299-1320.

28. International HapMap Consortium, Frazer KA, Ballinger DG, et al. A second generation human haplotype map of over 3.1 million SNPs. Nature. 2007;449:851861.

29. Ionita-Laza I, Lee S, Makarov V, Buxbaum JD, Lin X. Sequence kernel association tests for the combined effect of rare and common variants. Am J Hum Genet. 2013;92:841-853.

30. Wu MC, Lee S, Cai T, Li Y, Boehnke M, Lin X. Rare-variant association testing for sequencing data with the sequence kernel association test. Am J Hum Genet. 2011;89:82-93.

31. Patterson N, Price AL, Reich D. Population structure and eigenanalysis. PLoS Genet. 2006;2:e190.

32. Price AL, Patterson NJ, Plenge RM, Weinblatt ME, Shadick NA, Reich D. Principal components analysis corrects for stratification in genome-wide association studies. Nat Genet. 2006;38:904-909.

33. Gould HJ, Sutton BJ. IgE in allergy and asthma today. Nat Rev Immunol. 2008;8:205-217.

This article is protected by copyright. All rights reserved. 
34. Chiu YH, Macmillan JB, Chen ZJ. RNA polymerase III detects cytosolic DNA and induces type I interferons through the RIG-I pathway. Cell. 2009;138:576-591.

35. Tai AW, Benita Y, Peng LF, et al. A functional genomic screen identifies cellular cofactors of hepatitis C virus replication. Cell Host Microbe. 2009;5:298-307.

36. Liu Y, Wang X, Li S, et al. The role of von Willebrand factor as a biomarker of tumor development in hepatitis B virus-associated human hepatocellular carcinoma: a quantitative proteomic based study. J Proteomics. 2014;106:99-112.

37. Tang $\mathrm{R}$, Kong $\mathrm{F}$, Hu L, et al. Role of hepatitis $\mathrm{B}$ virus $\mathrm{X}$ protein in regulating LIM and $\mathrm{SH} 3$ protein 1 (LASP-1) expression to mediate proliferation and migration of hepatoma cells. Virol J. 2012;9:163.

38. Liu L, Li Y, Zhang S, Yu D, Zhu M. Hepatitis B virus X protein mutant upregulates CENP-A expression in hepatoma cells. Oncol Rep. 2012;27:168-173.

39. Manchia M, Cullis J, Turecki G, Rouleau GA, Uher R, Alda M. The impact of phenotypic and genetic heterogeneity on results of genome wide association studies of complex diseases. PLoS One. 2013;8:e76295.

40. Buster EH, Hansen BE, Lau GK, et al. Factors that predict response of patients with hepatitis $B$ e antigen-positive chronic hepatitis B to peginterferon-alfa. Gastroenterology. 2009;137:2002-2009.

41. Sonneveld MJ, Rijckborst V, Zeuzem S, et al. Presence of precore and core promoter mutants limits the probability of response to peginterferon in hepatitis B e antigen-positive chronic hepatitis B. Hepatology. 2012;56:67-75.

42. Wang YC, Yang SS, Su CW, et al. Predictors of response to pegylated interferon in chronic hepatitis B: a real-world hospital-based analysis. Sci Rep. 2016;6:29605.

This article is protected by copyright. All rights reserved. 
TABLES

Table 1 Baseline patient characteristics.

\begin{tabular}{|c|c|}
\hline Characteristic & $\begin{array}{c}\text { Total } \\
\mathrm{N}=1636\end{array}$ \\
\hline Male gender, $\mathrm{n}(\%)$ & $1173(72)$ \\
\hline Mean age, years $\pm S D$ & $39.0 \pm 11.0$ \\
\hline \multicolumn{2}{|l|}{ Self-reported race, n (\%) } \\
\hline Asian/Oriental & $1108(68)$ \\
\hline White & $465(28)$ \\
\hline Other & $63(4)$ \\
\hline \multicolumn{2}{|l|}{ HBeAg status, n (\%) } \\
\hline Positive & $907(55)$ \\
\hline Negative & $668(41)$ \\
\hline Unknown & $61(4)$ \\
\hline \multicolumn{2}{|l|}{ HBV genotype, n (\%) } \\
\hline A & $87(5)$ \\
\hline B & $339(21)$ \\
\hline C & $457(28)$ \\
\hline D & $243(15)$ \\
\hline Other/unknown & $510(31)$ \\
\hline Mean ALT, U/L $\pm S D$ & $121.6 \pm 133.8$ \\
\hline Mean HBV DNA, $\log _{10} \mathrm{IU} / \mathrm{mL} \pm \mathrm{SD}$ & $5.0 \pm 2.2$ \\
\hline
\end{tabular}

This article is protected by copyright. All rights reserved. 
Table 2 Efficacy outcomes according to analysis population.

\begin{tabular}{|c|c|c|c|c|}
\hline $\begin{array}{l}\text { Efficacy endpoint } \\
\text { (at } \geq 24 \text { weeks post-treatment) }\end{array}$ & $\begin{array}{l}\text { Analysis } \\
\text { population }\end{array}$ & $\begin{array}{l}\text { Nonresponders, } \\
\mathrm{n}(\%)\end{array}$ & $\begin{array}{l}\text { Responders, } \\
\text { n (\%) }\end{array}$ & $n$ \\
\hline \multirow{3}{*}{$\begin{array}{l}\text { HBeAg-positive patients: } \\
\text { 1. HBeAg seroconversion or } \\
\text { HBsAg clearance }\end{array}$} & EA & $564(69)$ & $255(31)$ & 819 \\
\hline & non-EA & $67(76)$ & $21(24)$ & 88 \\
\hline & ALL & $631(70)$ & $276(30)$ & $907^{\mathrm{a}}$ \\
\hline \multirow{3}{*}{$\begin{array}{l}\text { 2. HBeAg seroconversion } \\
\text { and } \mathrm{HBV}-\mathrm{DNA} \\
<2000 \mathrm{IU} / \mathrm{mL} \text {, or } \mathrm{HBsAg} \\
\text { clearance }\end{array}$} & EA & $644(79)$ & $175(21)$ & 819 \\
\hline & non-EA & $70(80)$ & $18(20)$ & 88 \\
\hline & ALL & $714(79)$ & $193(21)$ & 907 \\
\hline \multirow{3}{*}{$\begin{array}{l}\text { HBeAg-negative patients: } \\
\text { 3. HBV DNA <2000 IU/mL } \\
\text { or HBsAg clearance }\end{array}$} & EA & $58(22)$ & $209(78)$ & 267 \\
\hline & non-EA & $187(50)$ & $184(50)$ & 371 \\
\hline & All & $245(38)$ & 393 (62) & 638 \\
\hline \multirow{3}{*}{$\begin{array}{l}\text { All patients: } \\
\text { 4. Endpoints } 1 \text { and } 3 \\
\text { combined }\end{array}$} & EA & $622(57)$ & $464(43)$ & 1086 \\
\hline & non-EA & $254(55)$ & $205(45)$ & 459 \\
\hline & ALL & $876(57)$ & $669(43)$ & $1545^{a}$ \\
\hline \multirow{3}{*}{$\begin{array}{l}\text { 5. Endpoints } 2 \text { and } 3 \\
\text { combined }\end{array}$} & EA & $702(65)$ & $384(35)$ & 1086 \\
\hline & non-EA & $257(56)$ & $202(44)$ & 459 \\
\hline & ALL & 959 (62) & $586(38)$ & $1545^{a}$ \\
\hline \multirow{3}{*}{ 6. HBsAg clearance } & EA & $1015(93)$ & $80(7)$ & 1095 \\
\hline & non-EA & $384(94)$ & $24(6)$ & 408 \\
\hline & ALL & $1,399(93)$ & $104(7)$ & $1503^{b}$ \\
\hline
\end{tabular}

Three subgroups contain fewer than 30 patients.

ALL, all patients; EA, East Asian; HBeAg, hepatitis B 'e' antigen; HBsAg, hepatitis B surface antigen; HBV, hepatitis $B$ virus.

${ }^{a} 91$ patients were missing endpoint data.

${ }^{\mathrm{b}} 133$ patients were missing endpoint data. 
Table 3 Gene-based single nucleotide polymorphism (SNP) markers suggestive of association $\left(P<10^{-5}\right)$ with peginterferon alfa-2a response. Common variants have a minor allele frequency of $>5 \%$. The strength of genetic effect is illustrated by the odds ratio, whereby a score of $>3$ indicates a large effect size.

\begin{tabular}{|c|c|c|c|c|c|c|}
\hline Chromosome & SNP & Gene & MAF & OR & $P$-value & $\begin{array}{l}\text { Endpoint, } \\
\text { population } \\
\text { (model) }\end{array}$ \\
\hline 1 & $r s 7549785$ & FCER1A & 0.02 & 8.22 & $4.83 \times 10^{-7}$ & 6, EA (add/dom) \\
\hline \multirow{5}{*}{2} & \multirow{2}{*}{ rs9287655 } & \multirow{2}{*}{ ENSG151779 } & 0.44 & 0.66 & $1.37 \times 10^{-6}$ & $4, \mathrm{ALL}(\mathrm{add})$ \\
\hline & & & 0.44 & 0.64 & $1.18 \times 10^{-6}$ & 5, ALL (add) \\
\hline & rs 1550116 & \multirow{3}{*}{ CENPO } & 0.22 & 0.56 & $8.05 \times 10^{-6}$ & 5, EA (add) \\
\hline & rs2082881 & & 0.22 & 0.56 & $7.02 \times 10^{-6}$ & 5, EA (add) \\
\hline & rs1550115 & & 0.22 & 0.56 & $7.02 \times 10^{-6}$ & 5, EA (add) \\
\hline 3 & rs2302503 & LRRFIP2 & 0.42 & 0.37 & $9.50 \times 10^{-6}$ & 5, non-EA (dom) \\
\hline \multirow{2}{*}{4} & rs 1040084 & \multirow{2}{*}{$L N X 1$} & 0.31 & 2.37 & $4.26 \times 10^{-6}$ & 3, ALL (add) \\
\hline & rs 1913484 & & 0.34 & 2.36 & $4.35 \times 10^{-6}$ & 3, ALL (dom) \\
\hline 6 & rs2803073 & PARK2 & 0.42 & 1.5 & $3.39 \times 10^{-6}$ & 4, ALL (add) \\
\hline \multirow[b]{2}{*}{7} & $r s 10236906$ & HDAC9 & 0.17 & 0.57 & $8.46 \times 10^{-6}$ & 4, ALL (dom) \\
\hline & rs9691873 & CREBS & 0.09 & 2.32 & $9.46 \times 10^{-6}$ & 5, EA (add/dom) \\
\hline \multirow{5}{*}{9} & $r s 2370220$ & DMRT1 & 0.14 & 1.75 & $8.02 \times 10^{-6}$ & 5, ALL (dom) \\
\hline & rs 10814834 & GLISB & 0.38 & 0.46 & $7.38 \times 10^{-6}$ & 6, ALL (dom) \\
\hline & $r s 11139349$ & TLE1 & 0.27 & 1.84 & $9.52 \times 10^{-6}$ & 2, EA (add) \\
\hline & $r s 7042473$ & $\begin{array}{l}C D C 14 B \\
C D C 14 C\end{array}$ & 0.26 & 1.71 & $4.97 \times 10^{-6}$ & 4, ALL (dom) \\
\hline & $r s 10491723$ & CORO2A & 0.37 & 2.11 & $4.51 \times 10^{-6}$ & 6, ALL (add) \\
\hline 10 & $r s 1411283$ & ANKRD26 & 0.48 & 0.49 & $9.25 \times 10^{-6}$ & 1, ALL (dom) \\
\hline 11 & $r s 2279519$ & GRAMD1B & 0.21 & 1.75 & $8.02 \times 10^{-6}$ & 5, ALL (dom) \\
\hline \multirow{3}{*}{12} & rs216312 & $V W F$ & 0.36 & 0.66 & $5.31 \times 10^{-6}$ & 5, ALL (dom) \\
\hline & \multirow{2}{*}{ rs7968170 } & \multirow{2}{*}{ ERA } & 0.50 & 0.49 & $4.50 \times 10^{-6}$ & 4, EA (dom) \\
\hline & & & 0.50 & 0.46 & $4.87 \times 10^{-6}$ & 5, EA (dom) \\
\hline \multirow{2}{*}{14} & rs8012912 & \multirow{2}{*}{ SMOC1 } & 0.41 & 1.62 & $7.29 \times 10^{-6}$ & 5, EA (add) \\
\hline & rs11158827 & & 0.42 & 1.62 & $8.28 \times 10^{-6}$ & 5, EA (add) \\
\hline \multirow[b]{2}{*}{15} & $r s 6576456$ & ATP10A & 0.27 & 0.41 & $7.57 \times 10^{-6}$ & 3, ALL (dom) \\
\hline & rs2899723 & $\mathrm{IQCH}$ & 0.36 & 2.04 & $2.89 \times 10^{-6}$ & 3, ALL (add) \\
\hline \multirow{3}{*}{17} & rs646097 & $\angle A S P 1$ & 0.36 & 0.46 & $9.45 \times 10^{-6}$ & 2, ALL (dom) \\
\hline & rs 11868362 & MSI2 & 0.15 & 0.34 & $4.07 \times 10^{-6}$ & $2, \mathrm{EA}$ (add/dom) \\
\hline & $r s 16943470$ & YPEL2 & 0.06 & 2.97 & $5.21 \times 10^{-6}$ & 6, ALL (dom) \\
\hline
\end{tabular}

add, additive; ALL, all patients; OR, odds ratio; dom, dominant; EA, East Asian; $\mathrm{MAF}$, minor allele frequency;

This article is protected by copyright. All rights reserved. 


\section{FIGURE LEGENDS}

Figure 1. Biplot for principal components analysis of ancestry. (A) HapMap reference data; 988 subjects with four ancestry clusters evident (Chinese and Japanese, Mexican and Indian, Northern/Western European, and African). (B) 1636 GWAS patients overlaid on HapMap data; East Asian $(n=1120)$ and non-East Asian (516) subgroups represented by black and grey crosses. GWAS, genome-wide association study.

Figure 2. (A) Manhattan plot for HBsAg clearance endpoint, in the East Asian subgroup under an additive model of inheritance. Horizontal blue and red lines depict thresholds for suggestive $\left(P<1 \times 10^{-5}\right)$ and genome-wide significant $\left(P<5 \times 10^{-8}\right)$ associations. SNP rs7549785 for FCER1A gene $\left(P=4.83 \times 10^{-7}\right)$ shown. (B) Corresponding Quantile-Quantile plot. Diagonal $(X=Y)$ red line representing the expected distribution of association $P$-values. Observed $P$-values shown by blue circles.

HBsAg, hepatitis B surface antigen; SNP, single nucleotide polymorphism.

Figure 3. Genomic context of FCER1A gene. (A) Univariate association plot, under an additive model of inheritance, for markers in FCER1A plus 10 kilobase flanking sequence. (B) Linkage disequilibrium analysis of markers in FCER1A; red shading indicates high pairwise correlation (linkage disequilibrium) between the markers.

This article is protected by copyright. All rights reserved. 
A HapMap $(n=988)$

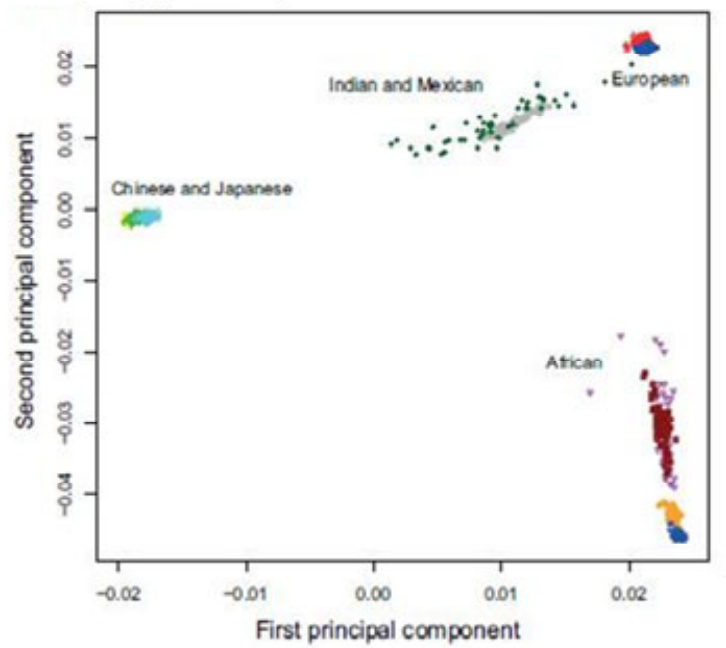

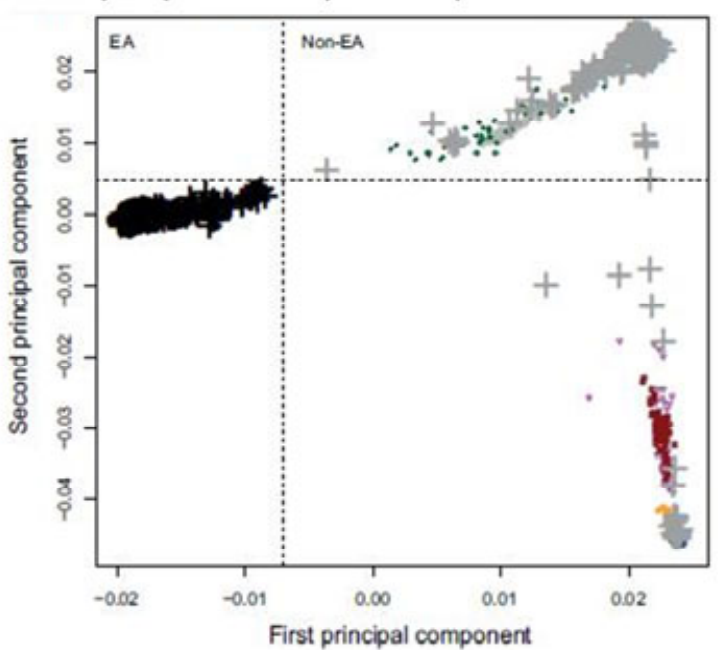

$\triangle$ CEU + CHB $\nabla$ ASW + MEX \& LWK a MIK \& TSI $=$ CHD $\times$ YRI \& JPT * CIH

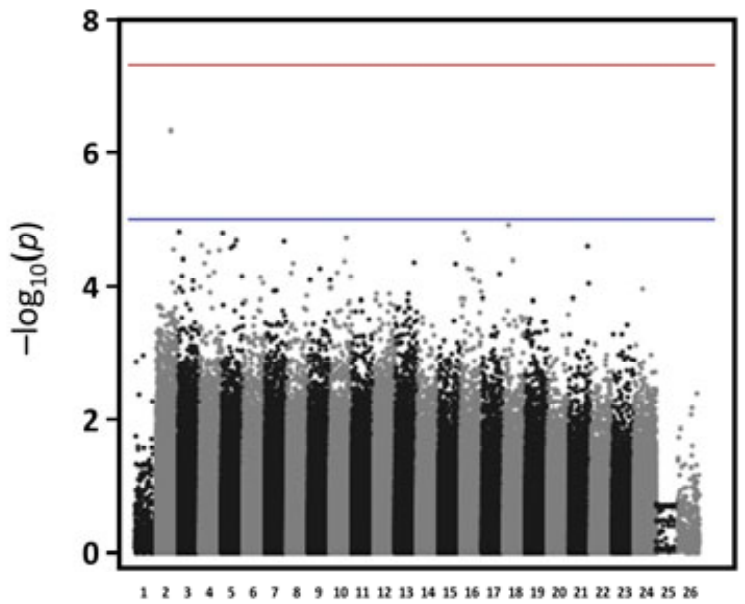

Chromosome

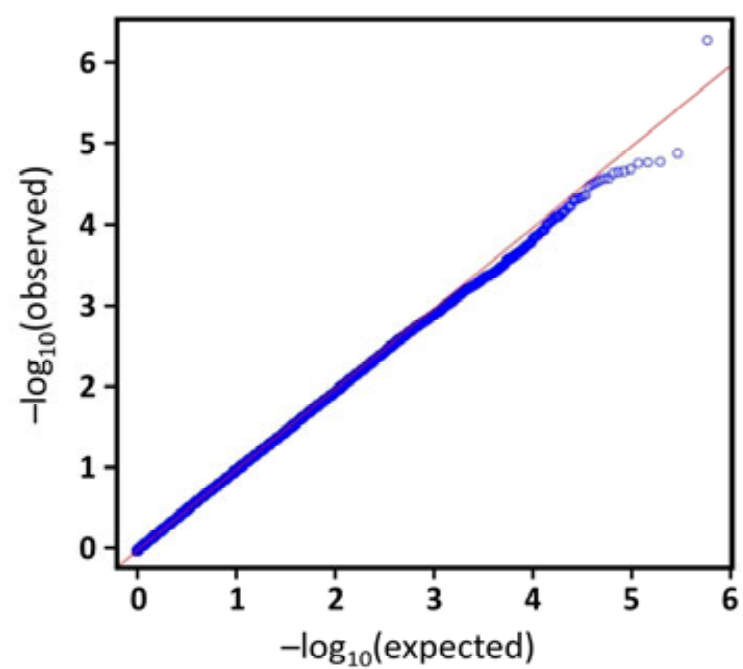

This article is protected by copyright. All rights reserved. 
A

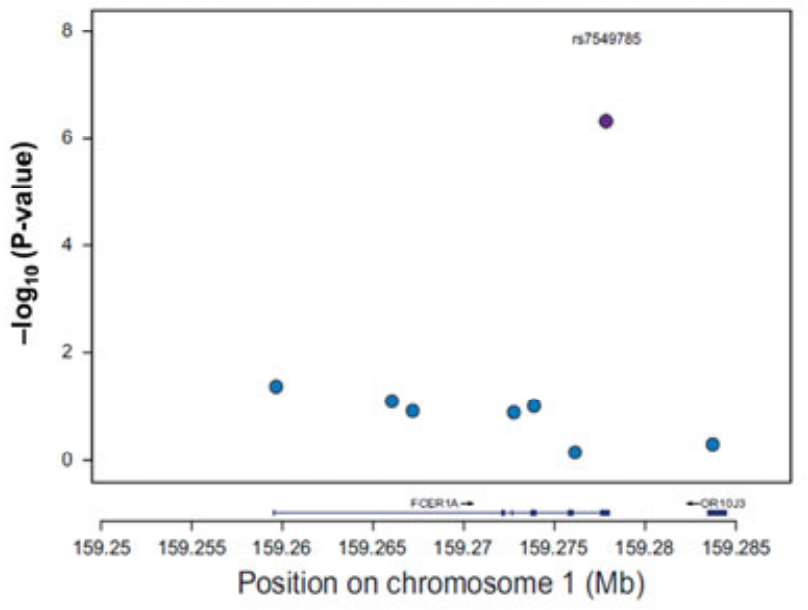

B
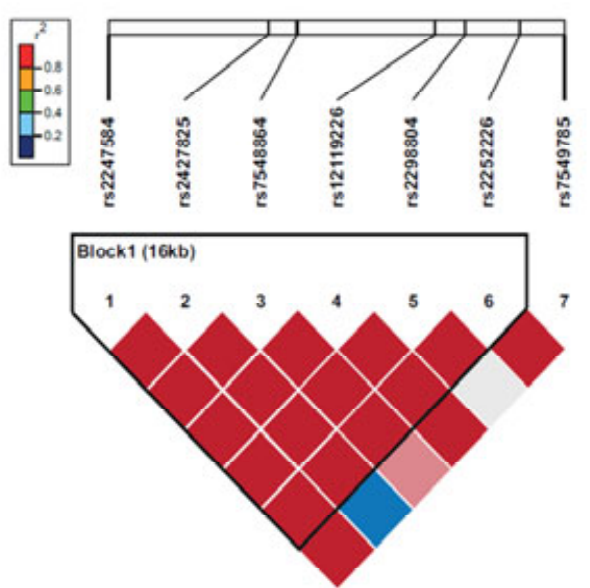

This article is protected by copyright. All rights reserved. 